\title{
A Simple Hysteretic Constitutive Model for Unsaturated Flow
}

\author{
Mariangeles Soldi $^{1}$ - Luis Guarracino ${ }^{1}$. \\ Damien Jougnot ${ }^{2}$
}

Received: 29 November 2016 / Accepted: 19 August 2017

(C) Springer Science+Business Media B.V. 2017

\begin{abstract}
In this paper, we present a constitutive model to describe unsaturated flow that considers the hysteresis phenomena. This constitutive model provides simple mathematical expressions for both saturation and hydraulic conductivity curves, and a relationship between permeability and porosity. The model is based on the assumption that the porous media can be represented by a bundle of capillary tubes with throats or "ink bottles" and a fractal pore size distribution. Under these hypotheses, hysteretic curves are obtained for saturation and relative hydraulic conductivity in terms of pressure head. However, a non-hysteretic relationship is obtained when relative hydraulic conductivity is expressed as a function of saturation. The proposed relationship between permeability and porosity is similar to the well-known Kozeny-Carman equation but depends on the fractal dimension. The performance of the constitutive model is tested against different sets of experimental data and previous models. In all of the cases, the proposed expressions fit fairly well the experimental data and predicts values of permeability and hydraulic conductivity better than others models.
\end{abstract}

Keywords Constitutive model - Unsaturated flow · Hysteresis phenomena - Saturation · Hydraulic conductivity

\section{Introduction}

Constitutive models for unsaturated flow provide relationships between saturation (or water content), hydraulic conductivity and pressure head. These relationships define the hydraulic behavior of soils and are necessary for the numerical resolution of the nonlinear Richards equation (Richards 1931). From a numerical point of view, it is desirable that the math-

Mariangeles Soldi

msoldi@fcaglp.unlp.edu.ar

1 Facultad de Ciencias Astronómicas y Geofísicas, Universidad Nacional de La Plata,

Consejo Nacional de Investigaciones Científicas y Técnicas, La Plata, Argentina

2 UPMC Univ Paris 06, CNRS, EPHE, UMR 7619 METIS, Sorbonne Universites, Paris, France 
ematical expressions of the constitutive model have simple analytical forms with a small number of parameters in order to reduce the computational cost of each iteration of the linearization method. In the last decades, several empirical and semi-empirically models have been proposed, being the most widely used the van Genuchten (1980) and the Brooks and Corey (1964) models. Van Genuchten proposed an empirical relation for saturation to obtain a closed-form analytical expression for the hydraulic conductivity by using Burdine (1953) and Mualem (1976) predictive models. Similarly, the Brooks and Corey model combines a power-law relation for saturation with Burdine model to obtain a simple closed-form analytical expression for the hydraulic conductivity. More recently, Assouline et al. (1998) proposed a conceptual model for saturation based on the assumption that the soil structure results from a uniform random fragmentation process. Then, Assouline (2001) developed a model to predict the relative hydraulic conductivity based on the first two moments of the water retention curve. In the particular case of fractured rocks, a physical constitutive model based on fractal geometry has been proposed by Guarracino (2006) and Monachesi and Guarracino (2011).

Constitutive models describe hydraulic parameters at the representative elementary volume (REV) scale. The water flow in a REV is usually described by capillary tube models with different shapes and pore size distributions. Most models assume circular cross-sectional capillary tubes, but recently Wang et al. (2015) proposed a permeability model assuming arbitrary cross-sectional shapes of the tubes. Different approaches have been introduced to represent pore size distributions, e.g., multimodal, Gaussian and fractal distributions (e.g., Rubin 1967; Topp 1971; Poulovassilis and Tzimas 1975; Jerauld and Salter 1990; Xu and Torres-Verdín 2013; Guarracino et al. 2014). Fractal distribution are commonly used to characterize porous media due to its simplicity and its capacity to describe a wide range of problems and soil textures (e.g., Tyler and Wheatcraft 1990; Yu et al. 2003; Yu and Li 2001). In particular, Ghanbarian-Alavijeh et al. (2011) propose a fairly recent review that illustrates the use of fractals to parameterize water retention curves.

Hydraulic properties of porous media present hysteresis phenomena which can significantly influence the flow and transport in partially saturated soils (e.g., Rubin 1967; Topp 1971; Poulovassilis and Tzimas 1975; Jerauld and Salter 1990). Hysteresis refers to the nonunique relationships between pressure head and both saturation and hydraulic conductivity. This phenomena depends on the water movement history during the imbibition and drying processes and is mainly believed to be caused by irregularities in the cross section of the pores or "ink-bottle" effects, contact angle effects or entrapped air (Jury et al. 1991; Klausner 1991). Modeling of hysteresis requires knowledge of at least one branch of the main hysteresis loop (Mualem 1977). In their review, Pham et al. (2005) divided hysteretic models into two main groups: domain models or physically based (e.g., Néel 1942; Mualem 1973) and empirical models (e.g., Feng and Fredlund 1999; Karube and Kawai 2001).

In this study, we derive a constitutive model for unsaturated flow assuming a porous media conceptualized as a bundle of constrictive capillary tubes with a fractal pore size distribution. The tubes present pore throats or "ink bottles" that allow to introduce the hysteresis in a simple form and also to characterize soils with high porosity and low permeability. Analytical closedform expressions are obtained for saturation and hydraulic conductivity curves which are easy to evaluate and show a good agreement with experimental data. The proposed expressions have four independent physical and geometrical parameters: the fractal dimension of the pore size distribution, a radial factor that characterize the size of the pore throat, and the maximum and minimum values of pressure head. In addition, an expression for the permeability as a function of porosity is obtained from the proposed model which becomes similar to the Kozeny-Carman equation but shows a better agreement with different experimental data sets. 
Fig. 1 Pore geometry of a single capillary tube with periodic pore throats

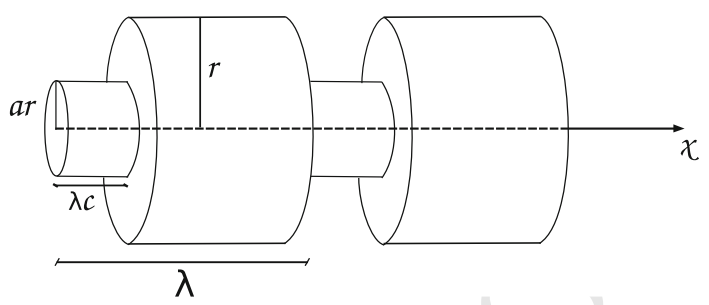

\section{Constitutive Model}

In this section, we derive closed-form analytical expressions for saturation and hydraulic conductivity curves. First, we present the pore geometry of the proposed model and we derive some hydraulic properties which are valid for a single pore. Then, assuming a cylindrical REV of porous media with a fractal pore size distribution, we obtain expressions for porosity, saturated hydraulic conductivity, and saturation and relative hydraulic conductivity curves.

\subsection{Hydraulic Description at Pore Scale}

The porous media is represented by a bundle of constrictive capillary tubes. Each pore is conceptualized as a cylindrical tube of radius $r$ and length $L$ with periodically throats represented by a segment of the tube with a smaller radius, as illustrated in Fig. 1.

Assuming that the pore geometry has a wavelength $\lambda$ and that the length of the tube $L$ contains an integer number $N$ of wavelengths, the pore radius along the tube can be described as follows:

$$
r(x)=\left\{\begin{array}{l}
a r \text { if } x \in[0+2 \pi n, \lambda c+2 \pi n) \\
r \text { if } x \in[\lambda c+2 \pi n, \lambda+2 \pi n),
\end{array}\right.
$$

where $a$ is the radial factor $(0 \leq a \leq 1), c$ is the length factor of the pore throat $(0 \leq c \leq 1)$ and $n=0,1, \ldots, N-1$. The parameter $a$ represents the ratio in which the radius is reduced, and the parameter $c$ represents the fraction of $\lambda$ with a narrow neck. Note that if $c=1$ or $c=0$ we obtain a straight tube with radii $a r$ or $r$, respectively.

Based on the above assumptions, the volume of a single tube can be calculated by integrating the cross-sectional area over the length $L$ as follows:

$$
V_{\mathrm{p}}(r)=\int_{0}^{L} \pi r^{2}(x) \mathrm{d} x=N\left[\int_{0}^{\lambda c} \pi r^{2} \mathrm{~d} x+\int_{\lambda c}^{\lambda} \pi(r a)^{2} \mathrm{~d} x\right]=L \pi r^{2} f_{v}(a, c),
$$

where

$$
f_{v}(a, c)=a^{2} c+1-c
$$

$f_{v}$ is a factor that varies between 0 and 1 , and quantifies the reduction in pore volume due to the constrictivity of the tube. A density plot of $f_{v}$ is shown in Fig. 2a. Note that low values of parameter $c$ or large values of parameter $a$ produce small variations of the pore volume.

Under the assumption of laminar flow and ignoring the convergence and divergence of the flow, the volumetric flow rate of a pore with periodical varying aperture $Q_{\mathrm{p}}(r)$ can be approximated with (Bodurtha 2003; Bousfield and Karles 2004):

$$
Q_{\mathrm{p}}(r)=\frac{\rho g}{\mu}\left[\frac{1}{L} \int_{0}^{L} \frac{8}{\pi r^{4}(x)} \mathrm{d} x\right]^{-1} \frac{\Delta h}{L},
$$


(a) $f_{v}(a, c)$

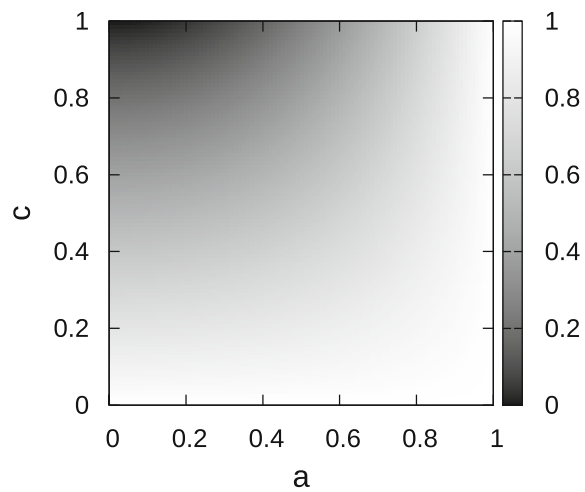

(b) $f_{k}(a, c)$

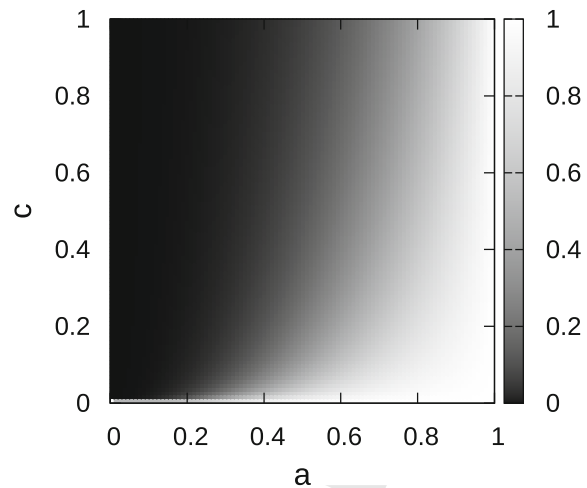

Fig. 2 Dimensionless factors $f_{v}(a, c)$ and $f_{k}(a, c)$. These factors control the pore volume and the volumetric flow rate at pore scale, and the porosity and saturated hydraulic conductivity at REV scale

where $\rho$ is the water density, $g$ gravity, $\mu$ water viscosity and $\Delta h$ the head drop across the tube.

Substituting Eq. (1) in Eq. (4) yields:

$$
Q_{\mathrm{p}}(r)=\frac{\rho g}{\mu} \frac{\pi r^{4}}{8} f_{k}(a, c) \frac{\Delta h}{L},
$$

where

$$
f_{k}(a, c)=\frac{a^{4}}{c+a^{4}(1-c)},
$$

$f_{k}$ is a factor that quantifies the volumetric flow rate reduction due to pore throats and varies between 0 and 1 . Figure $2 \mathrm{~b}$ shows the variation of $f_{k}$ as a function of the radial factor $a$ and the length factor $c$. As it can be expected, low values of $a$ drastically reduce the volumetric flow rate of the tube.

If we compare Fig. 2a, b, it can be noticed that the values of the parameters $a$ and $c$ modify the volume and the volumetric flow rate of the tube in different ways. For example, for low values of $a$ and $c$, the volume of the pore is slightly affected while the volumetric flow of the pore significantly decreases. Also note that for $a=1$ or $c=0, f_{v}=f_{k}=1$, and the expressions obtained for Eqs. (2) and (5) represent the volume and the volumetric flow rate of a straight tube of radius $r$, respectively.

\subsection{Hydraulic Description at REV Scale}

To derive the expressions for saturation and hydraulic conductivity, we consider as a REV a straight circular cylinder of radius $R$ and length $L$. The choice of the REV geometry is based on the shape of soil samples commonly used in laboratory tests. Other geometries, such as rectangular REV, can also be considered by introducing minor changes in model derivation. The pore structure of the REV is represented by a bundle of constrictive tubes (as described in the previous section) with a fractal pore size distribution. We also assume that the pore radius $r$ varies from a minimum value $r_{\min }$ to a maximum value $r_{\max }$. 
The cumulative size distribution of pores is assumed to obey the following fractal law (e.g., Tyler and Wheatcraft 1990; Yu 2008; Guarracino 2007):

$$
N(r)=\left(\frac{r}{R}\right)^{-D},
$$

where $D(1<D<2)$ is the fractal dimension. Note that if $r_{\max }=R, N=1$ and the REV is fully occupied by a single pore. On the other hand, if $r_{\min }=0$, the REV contains an infinite number of pores.

Differentiating Eq. (7) with respect to $r$, we obtain the number of pores whose sizes are within the infinitesimal range $r$ and $r+d r$ :

$$
\mathrm{d} N(r)=-D R^{D} r^{-D-1} \mathrm{~d} r .
$$

The negative sign in Eq. (8) implies that the pore number decreases with the increase in the pore size (Yu et al. 2003).

The porosity $\phi$ of the REV can be computed from its definition:

$$
\phi=\frac{\text { Volume of pore space }}{\text { Volume of REV }}=\frac{\int_{r_{\min }}^{r_{\max }} V_{\mathrm{p}}(r) \mathrm{d} N(r)}{\pi R^{2} L} .
$$

Replacing Eqs. (2) and (8) into Eq. (9), the porosity of the REV can be expressed as:

$$
\phi=f_{v} \phi^{\mathrm{ST}},
$$

where

$$
\phi^{\mathrm{ST}}=\frac{D}{R^{(2-D)}(2-D)}\left[r_{\max }^{2-D}-r_{\min }^{2-D}\right]
$$

is the porosity of the REV considering straight tubes (i.e., $a=1$ ).

The volumetric flow rate $Q$ at REV scale can be obtained by integrating all the pores volumetric flow rates given by Eq. (5) over the entire range of pore sizes:

$$
Q=\int_{r_{\min }}^{r_{\max }} Q_{\mathrm{p}}(r) \mathrm{d} N(r)=\frac{\rho g}{\mu} \frac{f_{k}}{8} \frac{\Delta h}{L} \frac{\pi D R^{D}}{(4-D)}\left[r_{\max }^{4-D}-r_{\min }^{4-D}\right] .
$$

On the other hand, on the basis of Darcy's law (1856), the volumetric flow rate through the REV can be expressed as:

$$
Q=K_{\mathrm{s}} \frac{\Delta h}{L} \pi R^{2},
$$

where $K_{\mathrm{s}}$ is the saturated hydraulic conductivity. Combining Eqs. (12) and (13), an expression for $K_{\mathrm{s}}$ is obtained:

$$
K_{\mathrm{s}}=f_{k} K_{\mathrm{s}}^{\mathrm{ST}}
$$

where

$$
K_{\mathrm{S}}^{\mathrm{ST}}=\frac{\rho g}{\mu} \frac{1}{8} \frac{D}{R^{(2-D)}(4-D)}\left[r_{\max }^{4-D}-r_{\min }^{4-D}\right]
$$

is the saturated hydraulic conductivity of the REV considering straight tubes.

By inspection of Eqs. (10) and (14), it can be noticed that the factors $f_{v}$ and $f_{k}$ produce different changes in the macroscale properties of the REV $\phi$ and $K_{\mathrm{s}}$, respectively. It can be demonstrated that for every value of parameters $a$ and $c, f_{k}$ is always smaller than $f_{v}$ 
allowing us to represent media with high porosity, low permeability and low specific surface area. Our model is also able to describe media which have the same porosity but different permeabilities. For example, clay and sand soils have typically similar porosities, but their hydraulic conductivities differ by several orders of magnitude (e.g., Carsel and Parrish 1988).

For most porous media, $r_{\min } / r_{\max } \simeq 10^{-2}$ (Yu and Li 2001); then, we can assume that $r_{\min } \ll r_{\max }$. Under the above assumption, the terms $r_{\min }^{2-D}$ and $r_{\min }^{4-D}$ in Eqs. (11) and (15) can be considered negligible. Then, combining the resulting expressions, we can obtain the following relationship between $K_{\mathrm{S}}$ and $\phi$ :

$$
K_{\mathrm{s}}=\alpha f_{k}\left[\frac{\phi}{f_{v}}\right]^{\left(\frac{4-D}{2-D}\right)},
$$

where

$$
\alpha=\frac{\rho g}{\mu} \frac{D R^{2}}{8(4-D)}\left[\frac{2-D}{D}\right]^{\left(\frac{4-D}{2-D}\right)} .
$$

Note that the exponent of porosity in Eq. $(16)(4-D) /(2-D)$ is greater than 3 . In the limit case of a cubic exponent, Eq. (16) becomes similar to the $\mathrm{KC}$ equation. This issue will be further analyzed in Sect. 3.1 where Eq. (16) is tested against experimental data sets.

\subsection{Saturation and Relative Hydraulic Conductivity Curves}

In this section, we derive the saturation and relative hydraulic conductivity curves of the constitutive model. Due to the varying aperture of the pores, the retention curves obtained from drainage and imbibition tests are expected to be different. The hysteresis phenomena can be easily introduced in the model thanks to the pore geometry illustrated in Fig. 1 and described by Eq. (1).

For a straight tube, we can relate the radius of the water-filled pore $r_{h}$ to the pressure head $h$ by the following equation (Jurin 1717; Bear 1998):

$$
h=\frac{2 \sigma \cos (\beta)}{\rho g r_{h}},
$$

where $\sigma$ is the surface tension of the water and $\beta$ the contact angle.

To obtain the main drying saturation curve, we consider that the REV is initially fully saturated and is drained by a pressure head $h$. We assume that a tube becomes fully desaturated if the radius of the pore throat $a r$ is greater than the radius $r_{h}$ given by Eq. (18). Then it is reasonable to also assume that pores with radii $r$ between $r_{\min }$ and $r_{h} / a$ will remain fully saturated. Therefore, according to Eqs. (2) and (8), the drying saturation curve $S_{e}^{\mathrm{d}}$ can be computed by:

$$
S_{e}^{\mathrm{d}}=\frac{\int_{r_{\text {min }}}^{\frac{r_{h}}{a}} V_{\mathrm{p}}(r) \mathrm{d} N(r)}{\int_{r_{\min }}^{r_{\max }} V_{\mathrm{p}}(r) \mathrm{d} N(r)}=\frac{\left(\frac{r_{h}}{a}\right)^{2-D}-r_{\min }^{2-D}}{r_{\text {max }}^{2-D}-r_{\text {min }}^{2-D}} .
$$

Substituting Eq. (18) into Eq. (19) yields

$$
S_{e}^{\mathrm{d}}(h)= \begin{cases}1 & \text { if } h \leq \frac{h_{\min }}{a} \\ \frac{(h a)^{D-2}-h_{\max }^{D-2}}{h_{\min }^{D-2}-h_{\max }^{D-2}} & \text { if } \frac{h_{\min }}{a} \leq h \leq \frac{h_{\max }}{a}, \\ 0 & \text { if } h \geq \frac{h_{\max }}{a}\end{cases}
$$


where

$$
h_{\min }=\frac{2 \sigma \cos (\beta)}{\rho g r_{\max }} \quad h_{\max }=\frac{2 \sigma \cos (\beta)}{\rho g r_{\min }},
$$

$h_{\min }$ and $h_{\max }$ being the minimum and maximum pressure heads defined by $r_{\max }$ and $r_{\min }$, respectively.

Similarly, the main wetting saturation curve can be obtained assuming that the REV is initially dry and it is flooded with a pressure $h$. In this case, only the tubes with radius $r$ smaller than $r_{h}$ will be fully saturated. Then the main wetting saturation curve $S_{e}^{\mathrm{W}}$ can be expressed as:

$$
S_{e}^{\mathrm{W}}(h)= \begin{cases}1 & \text { if } h \leq h_{\min } \\ \frac{h^{D-2}-h_{\max }^{D-2}}{h_{\min }^{D-2}-h_{\max }^{D-2}} & \text { if } h_{\min } \leq h \leq h_{\max } . \\ 0 & \text { if } h \geq h_{\max }\end{cases}
$$

Using the same hypothesis and neglecting film flow on tube surfaces, we can obtain the main drying and wetting curves for relative hydraulic conductivity. During drainage only tubes with pore throat radius $a r$ smaller than $r_{h}$ are fully saturated. Then, the main contribution to the total volumetric flow through the REV can be obtained by integrating the individual volumetric flow rates $Q_{\mathrm{p}}$ given by Eq. (5) over the pores that remain fully saturated $\left(r_{\min } \leq r \leq r_{h} / a\right)$ :

$$
Q=\int_{r_{\min }}^{\frac{r_{h}}{a}} Q_{\mathrm{p}}(r) \mathrm{d} N(r) .
$$

Otherwise, according to Buckingham-Darcy's law (Buckingham 1907), the total volumetric flow rate through the REV can be expressed as:

$$
Q=K_{\mathrm{s}} K_{\mathrm{r}}(h) \frac{\Delta h}{L} \pi R^{2},
$$

where $K_{\mathrm{r}}$ is the relative hydraulic conductivity which is a dimensionless function of $h$ and varies between 0 and 1 .

Combining Eqs. (23) and (24), and using Eqs. (5), (8) and (14), we obtain the relative hydraulic conductivity for the drying process:

$$
K_{\mathrm{r}}^{\mathrm{d}}=\frac{\left(\frac{r_{h}}{a}\right)^{4-D}-r_{\min }^{4-D}}{r_{\max }^{4-D}-r_{\min }^{4-D}} .
$$

Finally, using Eq. (18) we can express Eq. (25) in terms of pressure head:

$$
K_{\mathrm{r}}^{\mathrm{d}}(h)= \begin{cases}1 & \text { if } h \leq \frac{h_{\min }}{a} \\ \frac{(h a)^{D-4}-h_{\max }^{D-4}}{h_{\min }^{D-4}-h_{\max }^{D-4}} & \text { if } \frac{h_{\min }}{a} \leq h \leq \frac{h_{\max }}{a} . \\ 0 & \text { if } h \geq \frac{h_{\max }}{a}\end{cases}
$$


Similarly, the main wetting relative hydraulic conductivity curve $K_{\mathrm{r}}^{\mathrm{w}}(h)$ can be derived by integrating Eq. (23) over the range of saturated pores $\left(r_{\min } \leq r \leq r_{h}\right)$ :

$$
K_{\mathrm{r}}^{\mathrm{W}}(h)= \begin{cases}1 & \text { if } h \leq h_{\min } \\ \frac{h^{D-4}-h_{\max }^{D-4}}{h_{\min }^{D-4}-h_{\max }^{D-4}} & \text { if } h_{\min } \leq h \leq h_{\max } . \\ 0 & \text { if } h \geq h_{\max }\end{cases}
$$

Note that saturation and relative hydraulic conductivity expressions for both drying and wetting have analytical closed forms with only four independent parameters with geometrical and physical meaning: $a, D, h_{\min }$ and $h_{\max }$.

In the classical models of hysteresis, saturation and relative hydraulic conductivity values are limited by main drying and wetting curves which are obtained for initially fully saturated and dry porous media, respectively. For any intermediate state that does not correspond to a fully saturated or dry medium, scanning curves can be scaled from the main drying and wetting curves for both relationships, $S_{e}(h)$ and $K_{\mathrm{r}}(h)$. These scanning curves can be generated using different approaches such as play-type (Beliaev and Hassanizadeh 2001) or scaling hysteresis (Parker and Lenhard 1987).

Relative hydraulic conductivity $K_{\mathrm{r}}$ can also be expressed in terms of saturation $S_{e}$. By combining Eqs. (19) and (25), we obtain the following unique equation for the drying and the wetting:

$$
K_{r}=\frac{\left\{S_{e}\left[\left(\frac{h_{\min }}{h_{\max }}\right)^{D-2}-1\right]+1\right\}^{\frac{D-4}{D-2}}-1}{\left(\frac{h_{\min }}{h_{\max }}\right)^{D-4}-1} .
$$

It is interesting to remark that the relationship $K_{\mathrm{r}}\left(S_{e}\right)$ results in a non-hysteretic function across the entire range of saturations and this result is in agreement with a number of experimental data (e.g., van Genuchten 1980; Mualem and Klute 1986; Topp and Miller 1966).

For $h_{\max } \gg h_{\min }$, Eq. (28) can be reduced to:

$$
K_{\mathrm{r}}=S_{e}^{\frac{D-4}{D-2}}
$$

which is consistent with the well-known Brooks and Corey model, $K_{\mathrm{r}}=S^{\frac{2+3 \lambda}{\lambda}}$, where $\lambda$ is a dimensionless and empiric parameter related to the pore size distribution. Parameter $\lambda$ can be related to the fractal dimension $D$ through $\lambda=(D-2) /(1-D)$. Considering the range of $\lambda$ values between 0.21 and 3.02 reported by Assouline (2005) for different type of soils, it yields values of $D$ between 1.249 and 1.826 which are consistent with the admissible range of $D$ values.

\section{Comparison with Experimental Data}

In the present section, we test the ability of the proposed model to reproduce available measured data from the research literature. These data sets consist of measured permeabilityporosity, relative hydraulic conductivity-saturation, and hysteretic saturation-pressure head values for different soil textures. 
Table 1 Values of the fitted parameters $\left(D, C\right.$ and $\left.C_{\mathrm{KC}}\right)$ and the RMSD corresponding to the proposed model (Eq. 30) and to the KC equation (Eq. 32)

\begin{tabular}{llllll}
\hline Soil type & $D$ & $C(\mathrm{mD})$ & RMSD & $C_{\mathrm{KC}}(\mathrm{mD})$ & RMSD $_{\mathrm{KC}}$ \\
\hline Fluvial and deltaic & 1.68 & $1.336 \times 10^{7}$ & 1.1386 & 44.85 & 1.3856 \\
Timimoun Basin & 1.512 & $3.452 \times 10^{5}$ & 1.1894 & 75 & 1.3942 \\
Fine-grained sandstone & 1.498 & $1.797 \times 10^{6}$ & 0.5988 & $4.4 \times 10^{3}$ & 0.8910 \\
Silty sandstones & 1.524 & $5.1 \times 10^{5}$ & 0.5478 & $8.95 \times 10^{3}$ & 0.7680 \\
\hline
\end{tabular}

\subsection{Permeability}

In order to test the proposed relationship between permeability and porosity for different types of soils, we selected four data series from Luffel et al. (1991), Hirst et al. (2001) and Chilindar (1964). As it is well known, permeability $k$ and saturated hydraulic conductivity $K_{\mathrm{S}}$ are related through $K_{\mathrm{s}}=\mathrm{k \rho g} / \mu$. According to Eq. (16), the proposed permeability model can be expressed as follows:

$$
k=C \phi^{\left(\frac{4-D}{2-D}\right)},
$$

where

$$
C=\frac{\mu}{\rho g} \alpha f_{k} f_{v}^{\left(\frac{2-D}{4-D}\right)} .
$$

Equation (30) will be also compared with the Kozeny-Carman equation which reads (Kozeny 1927; Carman 1937):

$$
k=C_{\mathrm{KC}} \frac{\phi^{3}}{(1-\phi)^{2}},
$$

where $C_{\mathrm{KC}}$ is a parameter that depends on the specific internal surface area, an empirical geometrical parameter and the tortuosity.

For each type of soil, Eqs. (30) and (32) are fitted to measured data by minimizing the root-mean-square deviation (RMSD):

$$
\operatorname{RMSD}=\left\{\frac{1}{n} \sum_{i=1}^{n}\left[\log \left(k_{i}^{\text {calc }}\right)-\log \left(k_{i}^{\text {dat }}\right)\right]^{2}\right\}^{0.5},
$$

where $k^{\text {calc }}$ and $k^{\text {dat }}$ correspond to the calculated and measured permeabilities, respectively. A logarithmic scale was considered because of the wide range of variation for the permeability values. The fitted parameters for Eqs. (30) and (32) are listed in Table 1 as well as their respective RMSD. It can be noted that, for all soils, the RMSD of the proposed model is smaller than the ones from the KC equation. Figure 3 shows that the proposed relationship predicts fairly good the observed values over a range of 4-10 orders of magnitude.

\subsection{Relative Hydraulic Conductivity}

The proposed relative hydraulic conductivity model (Eq. 29) is tested against 8 experimental data series from the Mualem (1974) (see Table 2). These data series have been also used 

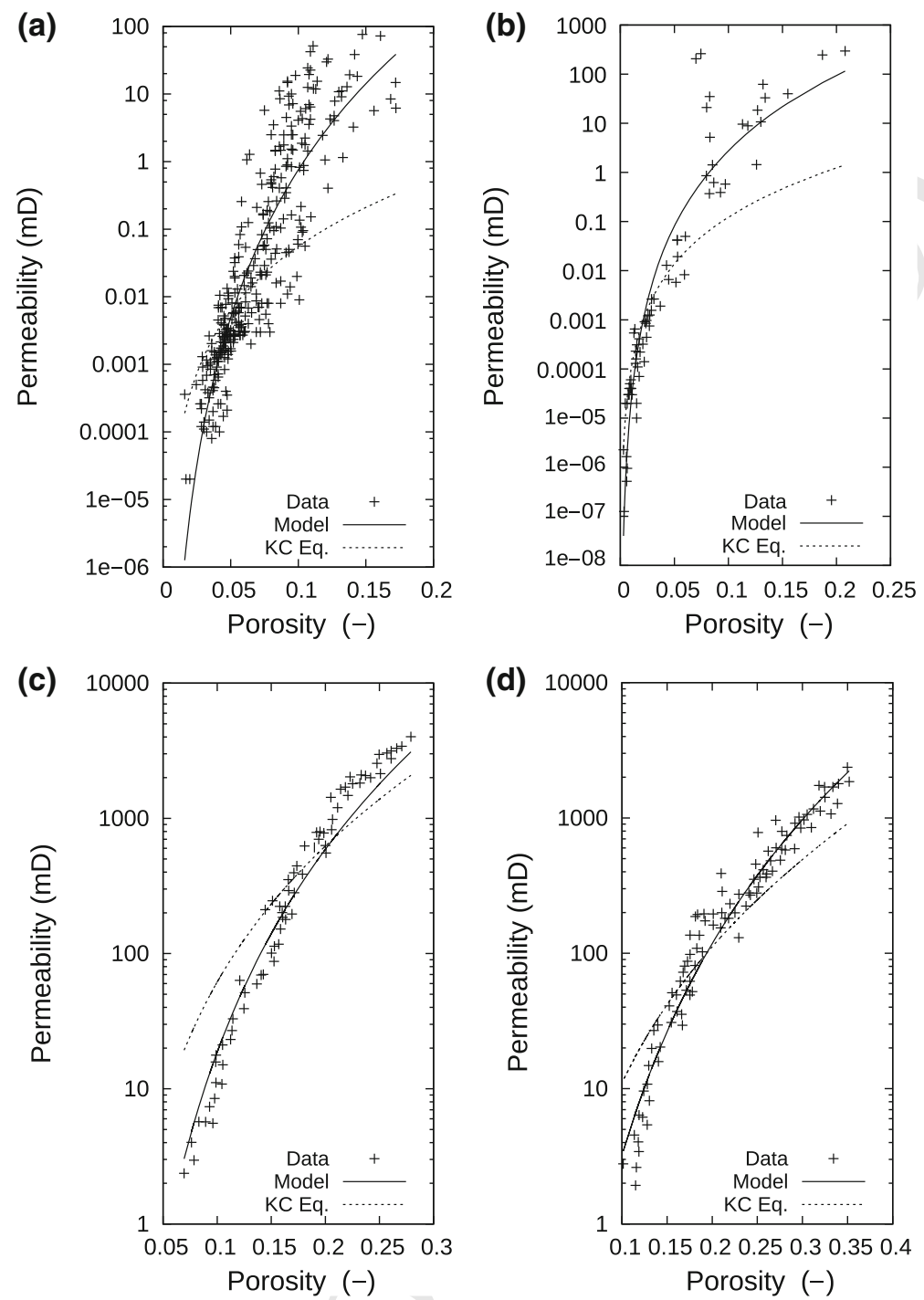

Fig. 3 Comparison between the proposed model, the KC equation and experimental data sets of permeabilityporosity. a Early Cretaceous Fluvial and Deltaic Channel Sandstones (data from Luffel et al. 1991), b Carboniferous and Devonian Timimoun Basin ("tight gas" sandstones) (data from Hirst et al. 2001), c finegrained sandstone and $\mathbf{d}$ silty sandstones (data from Chilindar 1964)

by Assouline to test his model which predicts $K_{\mathrm{r}}$ from the first two moments of the water retention (Assouline 2001). For each soil type, the proposed model is fitted to the measured data by minimizing the RMSD.

Figure 4 illustrates the fit of Eq. (29) and Assouline model to 2 sets of experimental data (Sable de Riviere and Gilat sandy loam) using the parameters given in Table 2. It can be noticed that the proposed model shows a significant improvement over the one of Assouline for the Gilat sandy loam (see Fig. 4b). Table 2 lists the resulting best fitted parameters for the

\section{包 Springer}


Table 2 Values of the fitted parameters ( $D$ and $h_{\min } / h_{\max }$ ), the corresponding RMSD and the RMSD of Assouline's model (2001)

\begin{tabular}{lllll}
\hline Soil type & $D$ & $\frac{h_{\min }}{h_{\max }}$ & RMSD & RMSD (Assouline) \\
\hline Sable de riviere & 1.99 & 0.101 & 0.015 & 0.036 \\
Gilat sandy loam & 1.012 & $1.09 \times 10^{-4}$ & 0.033 & 0.252 \\
Pouder river sand & 1.112 & $1.09 \times 10^{-4}$ & 0.071 & 0.076 \\
Amarillo silty clay loam & 1.387 & 0.001 & 0.009 & 0.014 \\
Rubicon sandy loam & 1.999 & 0.088 & 0.021 & 0.046 \\
Guelph loam & 1.918 & 0.021 & 0.004 & 0.037 \\
Weld silty clay loam & 1.508 & 0.061 & 0.036 & 0.038 \\
Silt Mont Cerris soils & 1.376 & $1.09 \times 10^{-4}$ & 0.082 & 0.188 \\
\hline
\end{tabular}
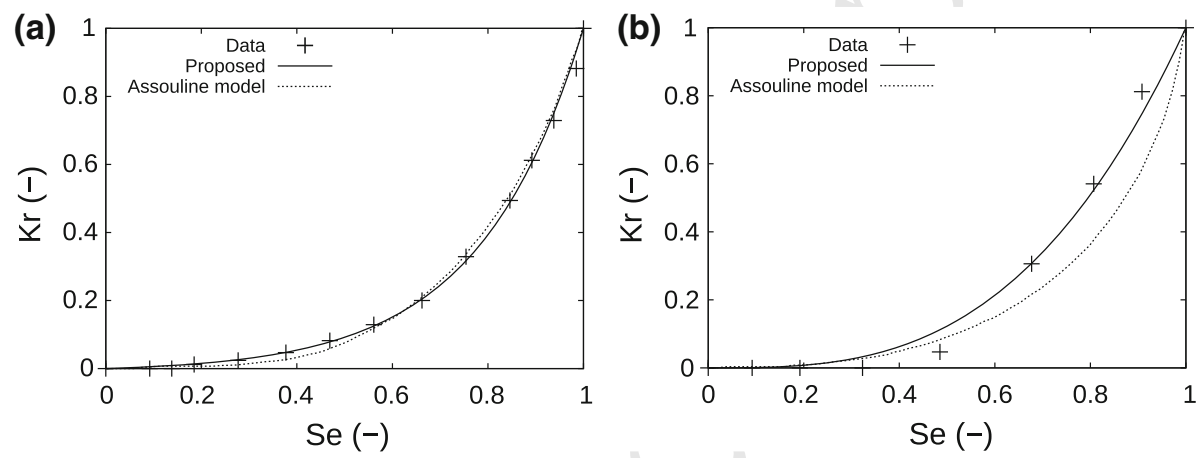

Fig. 4 Comparison between the relative hydraulic conductivity (Eq. 29) and measured data: a Sable de Riviere and b Gilat sandy loam (data from Mualem 1974). The figure also includes the fit of Assouline model (2001)

8 experimental data series, their RMSD and the corresponding RMSD obtained by Assouline (2001). For all soil types, the RMSD values of our model are smaller than the ones obtained with the Assouline model. Note that for Gilat sandy loam and Guelph loam soils, the RMSD is even 1 order of magnitude smaller.

\subsection{Saturation Curve Hysteresis}

To test the ability of the model to describe the hysteresis phenomena, we compare the main wetting and drying curves (Eqs. 20,22) to experimental data from the literature. Two different soil types from Pham et al. (2003) are used: Beaver Creek sand and a processed silt. The maximum and minimum values of pressure head (Eq. 21) were determined by try-and-error method (see Table 3). Then, the fractal dimension $D$ and the radial factor $a$ have been estimated by minimizing the RMSD between calculated and measured values of both drying and wetting curves using an exhaustive search method. Table 3 shows the model parameters and the RMSD values for each soil. Note that even if the model is simple, the hysteretic behavior of saturation can be fairly fitted by a minimum number of parameters. It is important to remark that only one set of parameters $a$ and $D$ explains both drying and wetting curves simultaneously (see Fig. 5). 
Table 3 Values of the fitted parameters ( $D$ and $a$ ) and the corresponding RMSD

\begin{tabular}{llllll}
\hline Soil type & $D$ & $a$ & $h_{\min }(\mathrm{m})$ & $h_{\max }(\mathrm{m})$ & RMSD \\
\hline Beaver Creek sand & 1.0266 & 0.4008 & 0.112 & 100.0 & $1.2566 \times 10^{-2}$ \\
Processed silt & 1.7598 & 0.4126 & 0.510 & 10.20 & $1.1178 \times 10^{-2}$ \\
\hline
\end{tabular}

Parameters $h_{\min }$ and $h_{\max }$ have been fixed before the estimation of $D$ and $a$
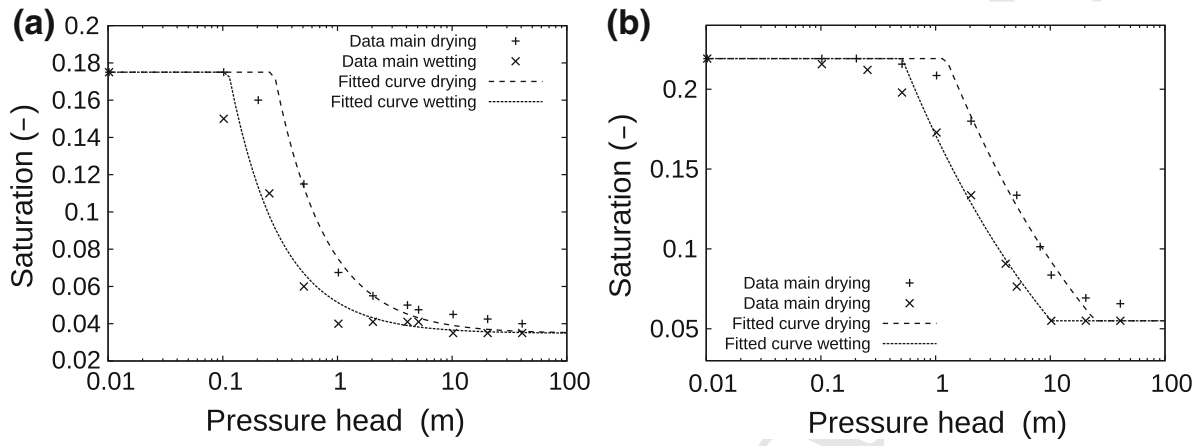

Fig. 5 Comparison of the main drying and wetting saturation curves from the proposed model with experimental data sets: a Beaver Creek sand and b processed silt (data from Pham et al. 2003)

Note that the expression of the drying curve (Eq. 20) depends on parameters $a$ and $D$. This enables us to fit these parameters using only experimental data from the main drying hysteresis loop and then to predict the main wetting curve by using Eq. (22). Following this alternative fitting procedure, the parameter values of the drying curve are: $a=0.627$ and $D=1.314\left(\right.$ RMSD $1.877 \times 10^{-2}$ ) for the Beaver Creek sand, and $a=0.401$ and $D=1.722$ (RMSD $1.362 \times 10^{-2}$ ) for the processed silt. Note that only the parameters of the processed silt are similar to the ones listed in Table 3. The prediction of the wetting curve from the drying curve could be an additional advantage of the proposed model that needs to be verified with a more exhaustive analysis and additional experimental data.

\section{Discussion and Conclusion}

A physically based theoretical model for estimating the hydraulic properties for unsaturated flow in porous media has been presented. The derivation of the model relies on the assumption that porous media can be represented by a bundle of cylindrical tubes with periodically throats and a fractal pore size distribution. Based on geometrical properties and physical laws, analytical closed-form expressions were obtained for the saturation and the relative hydraulic conductivity as functions of pressure head. These expressions contain four independent parameters $\left(a, D, r_{\min }\right.$ and $\left.r_{\max }\right)$, all of them with a specific physical or geometrical meaning. It is worth mentioning that the direct determination of these parameters is a difficult task due to the need to know in detail the microscopic geometry of the porous media. Considering the current developments in imaging technology, direct measurements of the pore structure can be obtained using X-ray tomography (Wildenschild 2002). Lindquist et al. (2000) applied this technique to measure distributions of channel length, throat size and pore volume of Fontainebleau sandstones. More recently, Dong and Blunt (2009) developed a max- 
imal ball algorithm to extract pore networks from X-ray tomography images and computed distributions of pore and throat size, pore spacing and pore shape factor of Fontainebleau and Berea sandstones.

Hysteresis in the saturation and relative hydraulic conductivity curves have been easily introduced in the model by assuming periodic constrictivities through the radial factor $a$ and the length factor $c$ (Fig. 1). It is interesting to note that when the relative hydraulic conductivity is expressed in terms of saturation a unique non-hysteretic relationship is obtained for both drainage and imbibition tests (Eq. 29). This behavior is consistent with previous studies and experimental data (Fig. 4; Topp and Miller 1966; van Genuchten 1980; Mualem and Klute 1986). Several causes have been proposed to justify hysteresis phenomena (e.g., Jury et al. 1991; Klausner 1991). These results enhance the hypothesis that hysteresis originates from pore throats or "ink-bottle" effects. Nevertheless, other effects could also explain or contribute to hysteresis in porous media, such as network effects, contact angle hysteresis and film flow (e.g., Blunt et al. 2002; Spiteri et al. 2008; Maineult et al. 2017). Note that when the radial factor $a=1$ (straight tubes), the hysteresis disappears from the saturation and relative hydraulic conductivity curves (see Sect. 2.3).

The presence of throats in the capillary tubes also modifies the porosity and permeability through the factors $f_{v}$ and $f_{k}$ (Eqs. 10,14), respectively. Both factors depend on $a$ and $c$, and vary between 0 and 1 (Eqs. 3,6). Nevertheless, the factor $f_{k}$ that modifies the permeability is always smaller than the factor $f_{v}$ that affects the porosity. This allows the model to describe media with high porosity, low permeability and low specific surface area, which cannot be properly represented with straight tube models.

The fractal dimension $D$ is a geometrical parameter that determines the pore size distribution of the model. This fractal distribution has been found to be useful to describe groundwater flow in the literature (e.g., Tyler and Wheatcraft 1990; Yu et al. 2003; Yu and Li 2001; Guarracino et al. 2014). The fractal dimension can be related to the pore size distribution index $\lambda$ proposed in the Brooks and Corey model (see Sect. 2.3), providing a geometrical meaning to this empirical parameter.

The proposed model also provides a relationship between permeability and porosity (Eq. 30), which under simplifying assumptions is similar to the KC equation. However, the proposed model performs better than the $\mathrm{KC}$ equation when compared to experimental permeability data ranging over 4-10 orders of magnitudes (Fig. 3).

This study allowed the development of a framework to describe saturation and relative hydraulic conductivity curves that include hysteresis phenomena. The relative hydraulic conductivity has been validated using experimental data from different type of soils, showing better agreements than Assouline model (Fig. 4). The hysteretic saturation curves have also been successfully tested with experimental data by fitting only 2 model parameters: $a$ and $D$ (Fig. 5).

From a mathematical point of view, all the expressions have analytical closed forms, which are simple and easy to evaluate. Therefore, their implementation in numerical flow codes is straightforward and involves little additional computational effort compared to non-hysteretic simulations.

This simple constitutive model can be a starting point to describe other physical phenomena that require hydraulic description at pore scale, such as generation of streaming potential (e.g., Jougnot et al. 2012), ionic transport and mixing in capillaries (e.g., Dentz et al. 2011), geochemical reactions in porous media (e.g., Guarracino et al. 2014) and wave-induced fluid flow (e.g., Rubino et al. 2013). 


\section{References}

Assouline, S., Tessier, D., Bruand, A.: A conceptual model of the soil water retention curve. Water Resour. Res. 34(2), 223-231 (1998)

Assouline, S.: A model for soil relative hydraulic conductivity based on the water retention characteristic curve. Water Resour. Res. 37(2), 265-271 (2001)

Assouline, S.: On the relationships between the pore size distribution index and characteristics of the soil hydraulic functions. Water Resour. Res. 41(7) (2005)

Bear, J.: Dynamics of Fluids in Porous Media. Dover Publications Inc., Mineola (1998)

Beliaev, A.Y., Hassanizadeh, S.M.: A theoretical model of hysteresis and dynamic effects in the capillary relation for twophase flow in porous media. Transp. Porous Media 43, 487-510 (2001)

Blunt, M.J., Jackson, M.D., Piri, M., Valvatne, P.H.: Detailed physics, predictive capabilities and macroscopic consequences for pore-network models of multiphase flow. Adv. Water Resour. 25(8), 1069-1089 (2002)

Bodurtha, P.: Novel Techniques for Investigating the Permeation Properties of Environmentally Friendly Paper Coatings: The Influence of Structural Anisotropy on Fluid Permeation in Porous Media. University of Plymouth, Plymouth (2003)

Bousfield, D.W., Karles, G.: Penetration into three-dimensional complex porous structures. J. Colloid Interface Sci. 270(2), 396-405 (2004)

Brooks, R.H., Corey, A.T.: Hydraulic properties of porous media and their relation to drainage design. Trans. ASAE 7(1), 0026-0028 (1964). doi:10.13031/2013.40684

Buckingham, E.: Studies on the Movement of Soil Moisture. Bulletin 38. USDA Bureau of Soils, Washington, DC (1907)

Burdine, N.: Relative permeability calculations from pore size distribution data. J. Pet. Technol. 5(03), 71-78 (1953)

Carman, P.C.: Fluid flow through granular beds. Trans. Inst. Chem. Eng. 15, 150-166 (1937)

Carsel, R.F., Parrish, R.S.: Developing joint probability distributions of soil water retention characteristics. Water Resour. Res. 24(5), 755-769 (1988)

Chilindar, G.V.: Relationship Between Porosity, Permeability and Grain Size Distribution of Sands and Sandstones, in Deltaic and Shallow Marine Deposits, vol. I, pp. 71-75. Elsevier, New York (1964)

Darcy, H.P.G.: Exposition et application des principes à suivre et des formules à employer dans les questions de distribution d'eau. In: Les fontaines publiques de la ville de Dijon. Victor Dalmont, Paris (1856)

Dentz, M., Le Borgne, T., Englert, A., Bijeljic, B.: Mixing, spreading and reaction in heterogeneous media: a brief review. J. Contam. Hydrol. 120, 1-17 (2011)

Dong, H., Blunt, M.J.: Pore-network extraction from micro-computerized-tomography images. Phys. Rev. E 80(3), 036307 (2009)

Feng, M., Fredlund, D.G.: Hysteretic influence associated with thermal conductivity sensor measurements. In: Proceedings from Theory to the Practice of Unsaturated Soil Mechanics, 52nd Canadian Geotechnical Conference and the Unsaturated Soil Group, Regina, 23-24 October, vol. 14, p. 2 (1999)

Guarracino, L.: A fractal constitutive model for unsaturated flow in fractured hard rocks. J. Hydrol. 324(1), 154-162 (2006)

Guarracino, L.: Estimation of saturated hydraulic conductivity $K_{S}$ from the van Genuchten shape parameter $\alpha$. Water Resour. Res. 43, W11502 (2007). doi:10.1029/2006WR005766

Guarracino, L., Rötting, T., Carrera, J.: A fractal model to describe evolution of multiphase flow properties during mineral dissolution. Adv. Water Resour. 67, 78-86 (2014)

Ghanbarian-Alavijeh, B., Millán, H., Huang, G.: A review of fractal, prefractal and pore-solid-fractal models for parameterizing the soil water retention curve. Can. J. Soil Sci. 91(1), 1-14 (2011)

Hirst, J.P.P., Davis, N., Palmer, A.F., Achache, D., Riddiford, F.A.: The tight gas challenge: appraisal results from the Devonian of Algeria. Pet. Geosci. 7, 13-21 (2001)

Jerauld, G.R., Salter, S.J.: The effect of pore-structure on hysteresis in relative permeability and capillary pressure: pore-level modeling. Transp. Porous Med. 5(2), 103-151 (1990)

Jougnot, D., Linde, N., Revil, A., Doussan, C.: Derivation of soil-specific streaming potential electrical parameters from hydrodynamic characteristics of partially saturated soils. Vadose Zone J. 11(1) (2012)

Jurin, J.: An account of some experiments shown before the royal society; with an enquiry into the cause of the ascent and suspension of water in capillary tubes. By James Jurin, MD and R. Soc. S. Philos. Trans. 30(351-363), 739-747 (1717)

Jury, W.A., Gardner, W.R., Gardner, W.H.: Soil Physics. Wiley, New York (1991)

Karube, D., Kawai, K.: The role of pore water in the mechanical behavior of unsaturated soils. Geotech. Geol. Eng. 19(3-4), 211-241 (2001)

Klausner, Y.: Fundamentals of Continuum Mechanics of Soils. Springer, New York (1991) 
Kozeny, J.: ijber kapillare Leitung des Wassers im Boden. Sitzungsber. Kais. Akad. Wiss. Wien. 136, 271-306 (1927)

Lindquist, W.B., Venkatarangan, A., Dunsmuir, J., Wong, T.F.: Pore and throat size distributions measured from synchrotron X-ray tomographic images of Fontainebleau sandstones. J. Geophys. Res. Solid Earth 105(B9), 21509-21527 (2000)

Luffel, D.L., Howard, W.E., Hunt, E.R.: Travis Peak core permeability and porosity relationships at reservoir stress. Soc. Pet. Eng. Form. Eval. 6(3), 310-318 (1991)

Maineult, A., Jougnot, D., Revil, A.: Variations of petrophysical properties and spectral induced polarization in response to drainage and imbibition: a study on a correlated random tube network. Geophys. J. Int. (2017)

Monachesi, L.B., Guarracino, L.: A fractal model for predicting water and air permeabilities of unsaturated fractured rocks. Transp. Porous Med. 90(3), 779-789 (2011)

Mualem, Y.: Modified approach to capillary hysteresis based on a similarity hypothesis. Water Resour. Res. 9(5), 1324-1331 (1973)

Mualem, Y.: A Catalogue of the Hydraulic Properties of Unsaturated Soils. Technion-Israel Institute of Technology, Haifa (1974)

Mualem, Y.: A new model for predicting the hydraulic conductivity of unsaturated porous media. Water Resour. Res. 12(3), 513-522 (1976)

Mualem, Y.: Extension of the similarity hypothesis used for modeling the soil water characteristics. Water Resour. Res. 13(4), 773-780 (1977)

Mualem, Y., Klute, A.: Hydraulic conductivity of unsaturated soils: prediction and formulas. In: Methods of Soil Analysis. Part 1. Physical and Mineralogical Methods, pp. 799-823 (1986)

Néel, L.: Théories des lois daimantation de Lord Rayleigh. Cah. Phys. 12, 1-20 (1942)

Parker, J.C., Lenhard, R.J.: A model for hysteretic constitutive relations governing multiphase flow 1. Saturation pressure relations. Water Resour. Res. 23(4), 618-624 (1987)

Pham, H.Q., Fredlund, D.G., Barbour, S.L.: A study of hysteresis models for soil-water characteristic curves. Can. Geotech. J. 42, 1548-1568 (2005). doi:10.1139/T05-071

Pham, H.Q., Fredlund, D.G., Barbour, S.L.: A practical model for the soil-water characteristic curve for soils with negligible volume change. Gotechnique 53(2), 293-298 (2003)

Poulovassilis, A., Tzimas, E.: The hysteresis in the relationship between hydraulic conductivity and soil water content. Soil Sci. 120(5), 327-331 (1975)

Richards, L.A.: Capillary conduction of liquids through porous mediums. J. Appl. Phys. 1(5), 318-333 (1931)

Rubin, J.: Numerical method for analyzing hysteresis-affected, post-infiltration redistribution of soil moisture. Soil Sci. Soc. Am. J. 31(1), 13-20 (1967)

Rubino, J.G., Guarracino, L., Müller, T.M., Holliger, K.: Do seismic waves sense fracture connectivity? Geophys. Res. Lett. 40(4), 692-696 (2013)

Spiteri, E.J., Juanes, R., Blunt, M.J., Orr, F.M.: A new model of trapping and relative permeability hysteresis for all wettability characteristics. Spe J. 13(03), 277-288 (2008)

Topp, G.C., Miller, E.E.: Hysteretic moisture characteristics and hydraulic conductivities for glass-bead media. Soil Sci. Soc. Am. J. 30(2), 156-162 (1966)

Topp, G.C.: Soil-water hysteresis: the domain theory extended to pore interaction conditions. Soil Sci. Soc. Am. J. 35(2), 219-225 (1971)

Tyler, S.W., Wheatcraft, S.W.: Fractal process in soil water retention. Water Resour. Res. 26(5), 1047-1054 (1990)

van Genuchten, M.T.: A closed-form equation for predicting the hydraulic conductivity of unsaturated soils. Soil Sci. Soc. Am. J. 44, 892-898 (1980)

Wang, S., Wu, T., Qi, H., Zheng, Q., Zheng, Q.: A permeability model for power-law fluids in fractal porous media composed of arbitrary cross-section capillaries. Physica A 437, 12-20 (2015)

Wildenschild, D., Vaz, C.M.P., Rivers, M.L., Rikard, D., Christensen, B.S.B.: Using X-ray computed tomography in hydrology: systems, resolutions, and limitations. J. Hydrol. 267(3), 285-297 (2002)

$\mathrm{Xu}, \mathrm{C}$., Torres-Verdín, C.: Pore system characterization and petrophysical rock classification using a bimodal Gaussian density function. Math. Geosci. 45(6), 753-771 (2013)

Yu, B.: Analysis of flow in fractal porous media. Appl. Mech. Rev. 61(5), 050801 (2008). doi:10.1115/1. 2955849

Yu, B., Li, J.: Some fractal characters of porous media. Fractals 9(03), 365-372 (2001)

Yu, B., Li, J., Li, Z., Zou, M.: Permeabilities of unsaturated fractal porous media. Int. J. Multiphas. Flow 29(10), 1625-1642 (2003) 
Journal: 11242

Article: 920

\section{Author Query Form}

\section{Please ensure you fill out your response to the queries raised below and return this form along with your corrections}

\section{Dear Author}

During the process of typesetting your article, the following queries have arisen. Please check your typeset proof carefully against the queries listed below and mark the necessary changes either directly on the proof/online grid or in the 'Author's response' area provided below

\begin{tabular}{|c|c|c|}
\hline Query & Details required & Author's response \\
\hline 1. & $\begin{array}{l}\text { Please check and confirm whether the } \\
\text { authors and their respective affiliations } \\
\text { have been correctly identified. Amend if } \\
\text { necessary. }\end{array}$ & \\
\hline 2. & $\begin{array}{l}\text { Kindly provide page range for the refer- } \\
\text { ences Assouline (2005) and Jougnot et al. } \\
\text { (2012). }\end{array}$ & \\
\hline 3. & $\begin{array}{l}\text { Kindly check and confirm the inserted } \\
\text { publication location is correct in refer- } \\
\text { ence Bodurtha (2003). }\end{array}$ & \\
\hline 4. & $\begin{array}{l}\text { Kindly check and confirm the reference } \\
\text { Buckingham (1907) is correctly identi- } \\
\text { fied. }\end{array}$ & \\
\hline 5. & $\begin{array}{l}\text { Kindly provide editor names for the ref- } \\
\text { erence Darcy (1856). }\end{array}$ & \\
\hline 6. & $\begin{array}{l}\text { Kindly check and confirm the inserted } \\
\text { publisher name is correct in reference } \\
\text { Jury et al. (1991). }\end{array}$ & \\
\hline 7. & $\begin{array}{l}\text { Kindly provide volume number and page } \\
\text { range for the reference Maineult et al. } \\
(2017) \text {. }\end{array}$ & \\
\hline 8. & $\begin{array}{l}\text { Kindly provide complete details for the } \\
\text { reference Mualem and Klute (1986). }\end{array}$ & \\
\hline
\end{tabular}

